\title{
Is There a Relationship between the Amount of Tissue Removed at Transurethral Resection of the Prostate and Clinical Improvement in Benign Prostatic Hyperplasia
}

\author{
Oliver W. Hakenberg, Christian Helke, Andreas Manseck, Manfred P. Wirth \\ Department of Urology, University Hospital Carl-Gustav Carus, Technical University, \\ Dresden, Germany
}

\begin{abstract}
Key Words
Benign Prostatic hyperplasia - Benign prostatic enlargement · Transurethral prostatectomy •

Prostate $\cdot$ Clinical outcome $\cdot$ Symptom scores $\cdot$ Organ weight
\end{abstract}

\begin{abstract}
Objective: To assess in a prospective trial the influence of the amount of tissue resected at transurethral resection of the prostate (TURP) for benign prostatic enlargement on the symptom improvement as assessed by symptom scores.

Methods: Between December 1996 and August 1998 a total of 138 men (mean age 68.2, range 53-89) with symptomatic benign prostatic enlargement who underwent TURP participated in this prospective study. Patients were assessed preoperatively with the International Prostate Symptom Score (IPSS), the American Urological Association Bother Score (AUA-BS) and the Benign Prostatic Hyperplasia Impact Index (BPH-II) as well as urinary flow rate measurements $\left(\mathrm{O}_{\max }\right)$ and prostate volume (PV) and residual urine determination by ultrasound. The amount of tissue resected was weighed. Patients were followed with reevaluation of $\mathrm{Q}_{\max }$, residual urine and the symptom and bother scores at 3 and 6 months.

Results: A close correlation between preoperative PV (mean $49.0 \mathrm{ml}$, SD 22.0, range 13-140) and the resected tissue weight (RTW, mean $24.7 \mathrm{~g}$, SD 18.0, range 6-128) was seen ( $r=0.75$, $p<0.001)$. Age was correlated with preoperative $P V(r=0.23, p<0.05)$. While significant mean improvements in $\mathrm{O}_{\max }$, residual volume and IPSS, AUA-BS and BPH-II were found 3 and 6 months postoperatively, a negative correlation was seen between the RTW and the IPSS, the AUA-BS and the BPH-II 3 months after TURP $(r=-0.23, p<0.024 ; r=-0.23, p<0.025 ; r=-0.20$, $p=0.05)$. No statistically significant correlation was seen between symptom change and the percentage of PV removed or the residual prostatic weight. Classification of the patients into groups depending on preoperative PV $(<30,31-50,51-70$ and $>70 \mathrm{ml})$ showed a tendency for patients with larger PV to gain more symptom improvement postoperatively.

Conclusions: Early symptom improvement after TURP will depend on the amount of tissue removed but the relationship is weak and affected by several other confounding factors. Appar-
\end{abstract}

\section{KARGER}

Fax +4161306 1234 E-Mail karger@karger.ch www.karger.com (c) 2001 S. Karger AG, Basel

0302-2838/01/0394-0412 \$17.50/0

Accessible online at:

www.karger.com/journals/eur
Oliver W. Hakenberg, MD

Klinik und Poliklinik für Urologie, Universitätsklinikum Carl-Gustav Carus

Fetscherstrasse 74

D-01307 Dresden (Germany)

Tel. +49 351458 2447, Fax +49 351458 4333, E-Mail hakenberg@ debitel.net 
ently, the symptomatic improvement after TURP is not primarily dependent on the relative completeness of the resection. Patients with larger prostates and larger RTW tend to gain more symptomatic benefit from TURP than do patients with smaller prostates.

Copyright @ 2001 S. Karger AG, Basel

\section{Introduction}

Transurethral resection of the prostate (TURP) is a safe and effective procedure [1] and remains the standard surgical treatment of benign prostatic hyperplasia (BPH) despite a variety of treatment alternatives [2]. Presently, the outcome of TURP is assessed in terms of symptom improvement as well as improvement in lower urinary tract function measured by simple urodynamic investigations of bladder emtying, i.e. flow rates and residual urine volume. Full urodynamic studies are not a routine investigation before TURP for most urologists in Germany [3].

The recommended technique of TURP consists of complete removal of all adenomatous tissue. However, the perioperative morbidity of TURP in terms of blood loss and fluid inflow is related to the size of the prostate. Hence, with the intention to reduce the morbidity of transurethral resection, limited resection techniques (minimal TURP, channel TURP) [4] have therefore been introduced and have gained some popularity. Other techniques of transurethral BPH treatment, such as transurethral needle ablation or interstitial laser coagulation do not aim at complete adenoma removal at all but rely on tissue sloughing or shrinkage in varying degrees $[5,6]$. With these different techniques and approaches to transurethral BPH treatment, the question of whether complete adenoma removal is required becomes important again.

While it is well known that there is little correlation between the size of the prostate gland and clinical measures of lower urinary tract function or lower urinary tract symptoms in $\mathrm{BPH}$, it is not entirely clear as to whether and how much outcome after TURP is related to the degree of ademona removal which is achieved.

We therefore conducted a prospective trial to determine the effect of the extent of tissue resection on symptom improvement after TURP in men with symptomatic benign prostatic enlargement.

\section{Patients and Methods}

Between December 1996 and August 1998, 138 patients were recruited for this prospective trial. Inclusion criteria were a definite indication for treatment by TURP (i.e. symptomatic benign prostatic enlargement with moderate-to-severe symptom severity and/or flow rate depression and/or residual urine volume $>100 \mathrm{ml}$ ) and written informed consent to participation in this clinical trial. Patients with a history of previous transurethral surgery of the prostate or prostate cancer were excluded as were patients with severe neurological diseases.

The trial was conducted according to GCP criteria and approved by the hospital's ethics committee.

Patients had been referred by private office urologist or the department's outpatient clinic with the indications for TURP given above. Preoperatively, all patients were evaluated by routine physical examination including a digital rectal examination, suprapubic ultrasound for the determination of prostate and residual urine volume (Siemens Versaline, Siemens, Munich, Germany) and urinary flow rate measurements (Dantec Flowmeter, Dantec, Denmark). A routine laboratory evaluation including prostate-specific antigen evaluation was done. Symptoms prior to surgery were assessed by a self-administered questionnaire containing all items of the International Prostate Symptom Score (IPSS) including the Quality of Life assessment (QoL), the American Urological Association Bother Score (AUA-BS) and the BPH Impact Index (BPH-II).

TURP was performed using standard 26-French resectoscopes (Wolf, Knittlingen, Germany) with the intermittent flow technique, by four different staff urologists according to the technique of complete adenoma resection down to the surgical capsule. The tissue resected was weighed in the operation theater immediately after the completion of TURP. 24-French irrigation catheters were placed and the balloon routinely blocked in the prostatic fossa with a volume corresponding to the amount of tissue removed. Irrigation was maintained until the next morning, and catheters were removed routinely on the 3rd day following TURP. Patients were usually discharged 1 day after catheter removal. On the day of discharge a urinary flow reading was taken.

Follow-up of the study patients was done with examinations 3 and 6 months after TURP, either by the referring office urologists or the outpatient clinic of the department. Follow-up included a clinical examination, determinations of flow rates and residual urine volume and the evaluation of symptom and bother scores using the identical selfadministered questionnaire.

Statistical analysis was done by comparison of means with the $\mathrm{t}$ test for paired or independent samples, as appropriate. Values are given as means \pm SD or SEM, as indicated. Correlation analysis was done using Spearman's or Pearson's correlation coefficient, as appropriate.

\section{Results}

The mean patient age was 68.22 years (SD 8.08, range 53-89), the mean preoperative prostate volume (PV) was $49.09 \mathrm{ml}$ (SD 22.03, range 6-40) and the mean weight of the resected tissue (RTW) was $24.75 \mathrm{~g}$ (SD 18.06, range 6-128). 


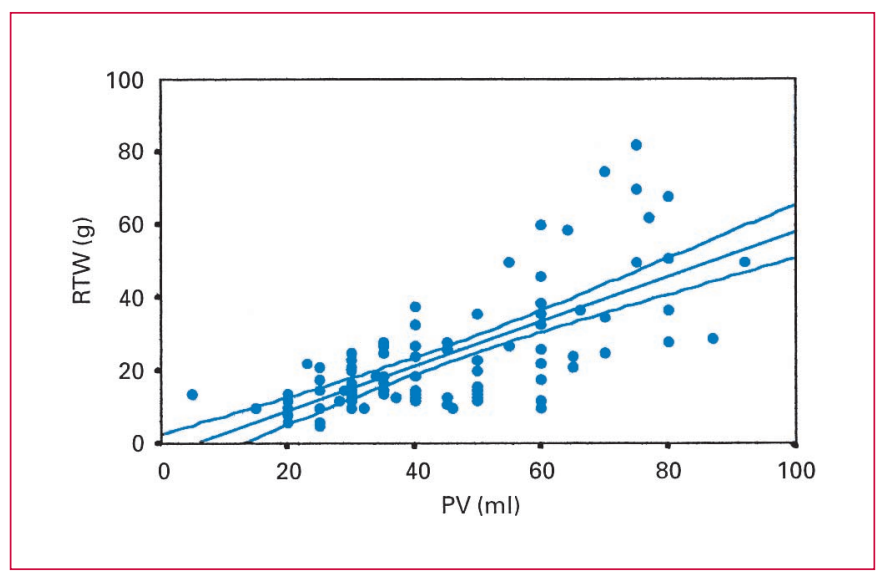

Fig. 1. Correlation between preoperative PV and RTW (linear regression with $95 \%$ confidence intervals).

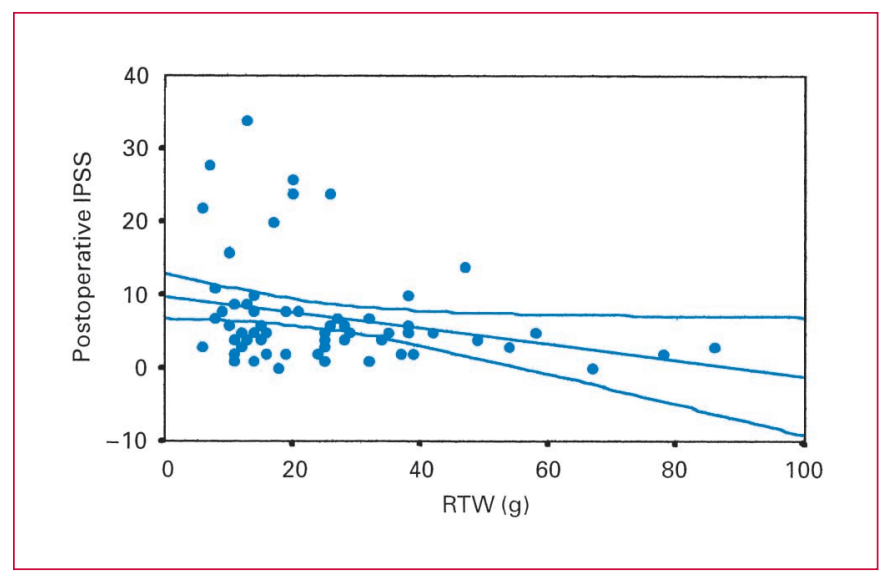

Fig. 2. IPSS at 3-month the follow-up versus RTW. Linear regression with $95 \%$ confidence intervals.

Table 1. Means $( \pm S D)$ of the evaluated parameters before and 3 and 6 months after TURP

\begin{tabular}{|c|c|c|c|c|c|c|}
\hline & $\mathrm{Q}_{\max }, \mathrm{ml} / \mathrm{s}$ & Residual urine, ml & IPSS (0-35) & AUA-BS (0-28) & BPH-II (0-) & QoL (0-6) \\
\hline $\begin{array}{l}\text { Preoperative } \\
\text { After TURP }\end{array}$ & $9.80 \pm 5.36$ & $101.7 \pm 80.3$ & $16.8 \pm 7.4$ & $10.89 \pm 6.8$ & $6.14 \pm 2.9$ & $3.70 \pm 1.4$ \\
\hline 3 months & $20.07 \pm 9.98^{b}$ & $9.84 \pm 17.9^{a}$ & $6.90 \pm 6.5^{b}$ & $5.01 \pm 6.4^{b}$ & $3.38 \pm 3.5^{b}$ & $1.59 \pm 1.5^{b}$ \\
\hline 6 months & $23.29 \pm 11.27$ & $9.85 \pm 23.7$ & $4.93 \pm 4.4^{\mathrm{a}}$ & $2.32 \pm 3.3^{b}$ & $1.73 \pm 2.5^{b}$ & $1.15 \pm 1.0^{\mathrm{a}}$ \\
\hline
\end{tabular}

Statistically significant differences compared to the previous measurement (3-month follow-up vs. baseline, 6-month follow-up vs. 3-month follow-up) ( ${ }^{\mathrm{a}} \mathrm{p}<0.05$, $\left.{ }^{\mathrm{b}} \mathrm{p}<0.01\right)$ are indicated.

The mean pre- and postoperative values of the parameters evaluated are given in table 1. Marked postoperative improvements were seen in flow rates, residual urine volume and symptom and bother scores. The $\mathrm{Q}_{\max }$ taken on the day of discharge, $24 \mathrm{~h}$ after catheter removal, was $18.28 \mathrm{ml} / \mathrm{s}$ (SD 9.04, range 5.7-48.7). The changes in $\mathrm{Q}_{\max }$, residual urine volume, IPSS, AUA-BS and BPH-II 3 and 6 months after TURP compared to preoperative values were marked and statistically significant (table 1).

Between the follow-up examinations at 3 and 6 months, no further significant changes in $\mathrm{Q}_{\max }$ or residual urine volume were seen, while significant further improvements in IPSS, AUA-BS, BPH-II and QoL were noted (table 1).

A significant correlation within the study group was seen between age and PV $(r=0.28, p<0.006)$ as well as between age and RTW $(r=0.29, p<0.002)$. PV and RTW were highly significantly correlated $(r=0.74, p<0.0001$; fig. 1$)$. There were no significant correlations between PV and either $\mathrm{Q}_{\max }$, residual urine volume, symptom or bother scores preoperatively, while the preoperative $\mathrm{Q}_{\max }$ correlated significantly with the preoperative IPSS $(r=-0.33, p<0.004)$.

Postoperatively, the RTW showed a significant correlation with the first $\mathrm{Q}_{\max }$ recording on the day of discharge $(\mathrm{r}=0.23, \mathrm{p}<0.03)$, but not with the subsequent $\mathrm{Q}_{\max }$ measured at 3 and 6 months postoperatively. The RTW also correlated negatively with the symptom and bother evaluation 3 months after TURP (IPSS: $r=-0.23, p<0.024$; AUA-BS: $\mathrm{r}=-0.23, \mathrm{p}<0.025$; BPH-II: $\mathrm{r}=-0.19, \mathrm{p}=0.05$; fig. 2 ), but not with the same parameters at the 6-month follow-up.

A residual prostatic weight ratio (RPWR, \%) was calculated (prostate volume -resected weight/prostate volume), giving the percentage of the PV remaining after TURP. The RPWR closely and negatively correlated with the RTW $(r=$ $-0.65, p<0.001)$ and was higher for smaller resected weights (fig. 3). The RPWR correlated negatively with age $(\mathrm{r}=-0.17, \mathrm{p}<0.05)$ and negatively with the 3 -month postoperative improvement in $\mathrm{Q}_{\max }(\mathrm{r}=-0.27, \mathrm{p}<0.05)$. Although there were weak negative correlations between the 


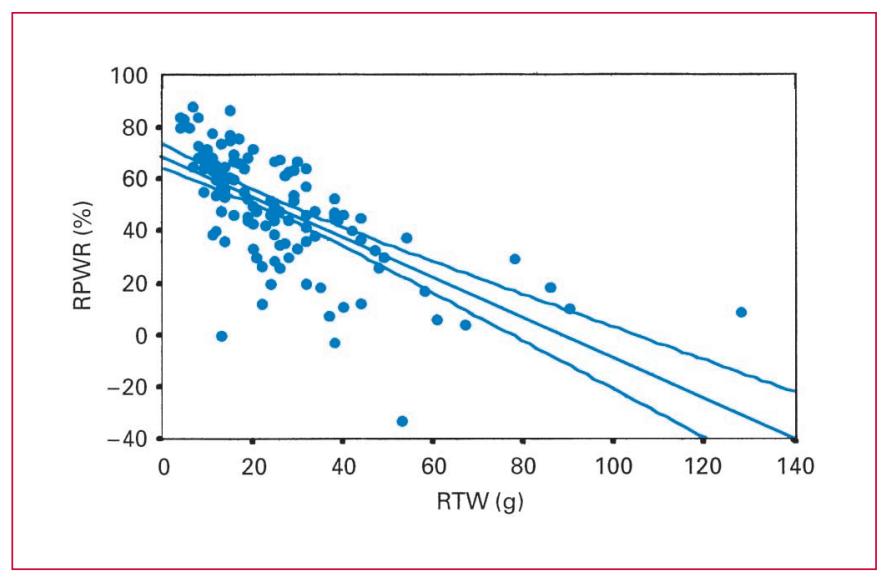

Fig. 3. RPWR (\%) versus RTW. Linear regression with $95 \%$ confidence intervals.

RPWR and the postoperative changes as well as the absolute postoperative symptom and bother scores these were not significant (e.g. RPWR vs. postoperative IPSS improvement at 3 months: $\mathrm{r}=-0.19, \mathrm{p}=0.083$ (fig. 4)).

Subgrouping patients depending on the preoperative prostate volume into groups with small $(<30 \mathrm{ml})$, medium $(31-50 \mathrm{ml})$, large $(51-70 \mathrm{ml})$ and very large $(>70 \mathrm{ml})$ prostates showed significant differences in the mean RTWs between these groups $(\mathrm{p}<0.01$ for each; table 2$)$. Between these four groups with increasing PVs, there was no significant difference in preoperative symptom or bother scores, $\mathrm{Q}_{\max }$ or residual volume, except for the group with the smallest prostates having a somewhat higher mean IPSS score preoperatively. There was a tendency for patients with larger prostates to be older on average and the mean age of the subgroup with very large prostates was significantly higher than that of those with small prostates $(p<0.05)$.

Postoperatively, there was a tendency for patients with larger PVs (and larger RTWs) to have better postoperative flow rates and lower postoperatives symptom and bother scores. However, although these tendencies may be seen in the results given in table 2, only a few of the differences reached statistical significance (lower postoperative IPSS and AUA-BS in patients with very large prostates $(<70)$, lower postoperative residual volume in patients with prostates sized $51-70 \mathrm{ml}$ ).

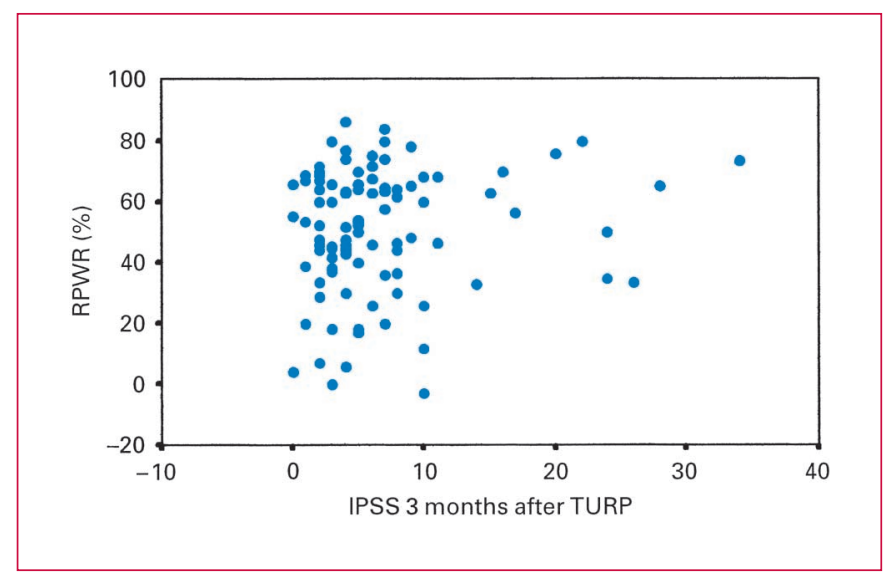

Fig. 4. IPSS at the 3-month follow-up versus RPWR.

\section{Discussion}

The conventional technique of transurethral resection aims at complete adenoma removal [7]. However, differences in individual surgeon's estimations exist regarding the extent of tissue removal still enabling uninhibited postoperative voiding. Thus, the completeness of adenoma removal by TURP is an area that is essentially under the control of the surgeon and might result in differences in postoperative outcome. Indeed, incomplete removal of the adenoma, as long as relief from obstruction is achieved, was advocated in order to reduce the morbidity of TURP.

There have been few investigations into the influence which the amount of resected tissue and the completeness of transurethral resection might have on outcome in BPH. For the patient, the most important outcome parameter is symptomatic improvement as assessed by symptom and bother scores [8-10].

In our study group, we found a close correlation between PV and age and a tendency for older men to have larger RTWs (table 2). A negative correlation was seen between postoperative symptoms and RTWs 3 months after TURP, while there was no correlation between the calculated RPWR and symptomatic outcome.

Possible methodological limitations of our study are that PV was measured by suprapubic rather than transrectal ultrasound, that residual prostatic weight was calculated rather than measured and that follow-up was limited to 6 months.

However, the close correlation between PV and RTW illustrates that generally both measurements were reliable and that complete or near complete adenoma resection was 
Table 2. Means ( \pm SD) of the evaluated parameters before (pre) and 3 months after TURP (post) in subgroups of patients with small, medium, large and very large preoperative prostate volumes

\begin{tabular}{|c|c|c|c|c|c|c|c|c|c|}
\hline \multirow{2}{*}{$\begin{array}{l}\text { Prostate } \\
\text { volume }\end{array}$} & \multirow{2}{*}{$\begin{array}{l}\text { Patients } \\
\mathrm{n}\end{array}$} & \multirow{2}{*}{$\begin{array}{l}\text { Age } \\
\text { years }\end{array}$} & \multirow{2}{*}{$\begin{array}{l}\text { RTW } \\
\text { g }\end{array}$} & \multicolumn{2}{|l|}{$\mathrm{Q}_{\max }, \mathrm{ml} / \mathrm{s}$} & \multicolumn{2}{|c|}{ Residual volume, ml } & \multicolumn{2}{|l|}{ IPSS (0-35) } \\
\hline & & & & pre & post & pre & post & pre & post \\
\hline$<30 \mathrm{ml}$ & 34 & $65.58 \pm 8.53$ & $12.1 \pm 5.2$ & $9.98 \pm 5.1$ & $17.1 \pm 7.4$ & $67.8 \pm 49.5$ & $18.7 \pm 27.3$ & $19.34 \pm 7.3$ & $9.64 \pm 8.8$ \\
\hline $31-50 \mathrm{ml}$ & 57 & $68.70 \pm 8.57$ & $21.5 \pm 9.3^{b}$ & $10.01 \pm 5.8$ & $21.2 \pm 8.5$ & $120.5 \pm 73.4^{a}$ & $7.9 \pm 12.3$ & $15.37 \pm 7.7^{a}$ & $5.89 \pm 5.7$ \\
\hline $51-70 \mathrm{ml}$ & 28 & $69.32 \pm 6.60$ & $33.2 \pm 15.7^{b}$ & $8.36 \pm 3.6$ & $23.0 \pm 13.3$ & $110.3 \pm 111.8$ & $2.2 \pm 6.0^{\mathrm{a}}$ & $17.40 \pm 7.1$ & $6.44 \pm 5.3$ \\
\hline$>70 \mathrm{ml}$ & 19 & $70.57 \pm 6.51^{b}$ & $46.7 \pm 29.5^{b}$ & $10.82 \pm 6.9$ & $16.6 \pm 9.2$ & $95.0 \pm 81.0$ & $10.2 \pm 17.8$ & $15.33 \pm 6.2$ & $4.38 \pm 2.2^{b}$ \\
\hline
\end{tabular}

${ }^{\mathrm{a}} \mathrm{p}<0.05,{ }^{\mathrm{b}} \mathrm{p}<0.01$ vs. the corresponding values for the group with small prostates.

achieved in most cases. While transrectal ultrasonography is considered to be more accurate than suprapubic ultrasound in prostate size determination, definite and similar limitations of accuracy exist for both methods [11, 12].

The negative correlation seen between the RTW and the postoperative symptom and bother scores at 3 months suggests that there may be a clinically significant relationship between these parameters. Figure 2 illustrates that patients with low RTW tended to have higher postoperative symptom scores. The fact that no such correlations were seen 6 months postoperatively does not necessarily contradict this conclusion since many other factors (prolonged tissue healing, scar formation, shrinkage of the prostatic fossa, adaption of the bladder to the altered outflow conditions) will influence the degree of lower urinary tract symptoms over the first 6 postoperative months. Individual symptom resolution after TURP may be prolonged in up to $15 \%$ of cases and can take up to 12 months $[13,14]$. The correlations between RTW and symptom and bother scores at 3 months, although statistically significant, were weak, which also suggests that the relationship is confounded.

Chen et al. [15] have described significant correlations between the improvement in American Urological Association symptom score and the calculated RPWR 4 months after TURP in a study group of 40 patients. In our study group which comprised considerably more patients, however, a significant correlation was demonstrable only between postoperative symptoms and the absolute RTW and not the RPWR.

The RPWR was smaller for larger RTWs in our study with a close and significant correlation (fig. 3). Thus in larger prostates, absolutely and relatively more tissue was resected and the RPWR was consequently lower. While the RPWR did not correlate with postoperative symptoms, it did correlate negatively with the postoperative $\mathrm{Q}_{\max }$.

These findings suggest that symptomatic outcome after TURP depends on the absolute RTW, i.e. the absolute size of the prostatic opening created rather than the relative ratio of resected tissue. Thus, patients with larger absolute RTW will therefore tend to gain more benefit from a TURP than those with small prostates, while the RPWR may be of relatively little importance. Supporting this conclusion is the finding of a significant correlation between the RTW and the first postoperative flow rate on the day after catheter removal, which was only slightly lower than the mean $\mathrm{Q}_{\max }$ ( \pm SD) 3 months postoperatively $(18.2 \pm 9.0$ vs. $20.07 \pm$ $9.9 \mathrm{ml} / \mathrm{s})$.

Our hypothesis that symptomatic outcome is dependent on the absolute amount of tissue resected is further supported by the subgroup analysis based on preoperative prostate size. This showed a tendency for patients with larger prostates to gain more symptom improvement after TURP. Except for the group with very large prostates $(>70 \mathrm{ml})$, there was a also tendency for better postoperative $\mathrm{Q}_{\max }$ with increasing preoperative prostate size (and hence increasing RTWs). It may be noted that the group with very large prostates also had the highest mean age. As detrusor function tends to become weaker with increasing age, this factor may be of influence as well and may account for the lower mean $\mathrm{Q}_{\max }$ in this subgroup.

These findings may have implications for the selection of patients for TURP as well as for the technique of TURP. Since patients with smaller prostates gain less symptomatic improvement from TURP than those with larger glands, alternative techniques might be considered in patients with small glands. For patients with very large glands, a TURP with limited resection and reduced morbidity may be appropriate. These questions should be addressed in future research trials with long-term postoperative follow-up. 


\begin{tabular}{|c|c|c|c|c|c|}
\hline \multicolumn{2}{|c|}{ AUA-BS (0-28) } & \multicolumn{2}{|c|}{ BPH-II (0-) } & \multicolumn{2}{|c|}{ QoL (0-6) } \\
\hline pre & post & pre & post & pre & post \\
\hline $11.86 \pm 8.4$ & $7.44 \pm 8.7$ & $5.84 \pm 3.4$ & $4.12 \pm 4.3$ & $3.92 \pm 1.5$ & $1.92 \pm 1.9$ \\
\hline $10.15 \pm 6.7$ & $4.62 \pm 6.1$ & $6.43 \pm 3.1$ & $3.14 \pm 3.3$ & $3.69 \pm 1.4$ & $1.31 \pm 1.3$ \\
\hline $11.36 \pm 6.8$ & $3.84 \pm 4.0$ & $5.35 \pm 2.8$ & $3.32 \pm 2.8$ & $3.44 \pm 1.5$ & $1.60 \pm 1.4$ \\
\hline $9.61 \pm 3.3$ & $2.69 \pm 3.52^{a}$ & $7.00 \pm 1.9$ & $2.38 \pm 3.2$ & $3.86 \pm 0.9$ & $1.61 \pm 1.2$ \\
\hline
\end{tabular}

\section{Conclusion}

The total amount of tissue removed at TURP for BPH rather than the RPWR does seem to have an influence on clinical outcome. This influence is measurable early after TURP but the correlations are weak and therefore probably influenced by other factors as well. Patients with larger prostates and hence larger absolute RTWs benefit more from a TURP in terms of symptom improvement than patients with smaller prostates. This may have implications for the selection of treatment modalities depending on prostate size.

\section{References}

1 Emberton M, Neal DE, Black N, Harrison M, Fordham M, McBrien MP, Williams RE, McPherson K, Devlin HB: The National Prostatectomy Audit: The Clinical management of patients during hospital admission. $\mathrm{Br}$ J Urol 1995;75:301-316.

2 Speakman MJ: Who should be treated and how? Evidence-based medicine in symptomatic BPH. Eur Urol 1999;36(suppl 3):40-51.

3 Berges RR, Pientka L: Management of the BPH syndrome in Germany: Who is treated and how? Eur Urol 1999;36(suppl 3):21-27.

4 Aagaard J, Jonler M, Fuglsig S, Christensen LL, Jorgensen HS, Norgaard JP: Total transurethral resection versus minimal transurethral resection of the prostate - A 10year follow-up study of urinary symptoms, uroflowmetry and residual volume. Br J Urol, 1994;74:333-336.

5 Jung P, Mattelaer P, Wolff, J, Merdorf A, Jakse G: Visual laser ablation of the prostate: Efficacy evaluated by urodynamics and compared to TURP. Eur Urol 1996;30:418-423.
6 Muschter R, Whitfield H: Interstitial laser therapy of benign prostatic hyperplasia. Eur Urol 1999;35:147-154.

7 Nesbit RM: Transurethral prostatic resection: in Campbell L, Harrison J (eds): Urology. Philadelphia, Sounders, 1970, p 2479.

8 Barry MJ, Fowler FJ, O'Leary M, Bruskewitz RJ, Holtgrewe HL, Mebust WK, Cockett AT: The American Urological Association symptom index for benign prostatic hyperplasia. The Measurement Committee of the American Urological Association. J Urol 1992;148: 1549-1555.

9 Hakenberg OW, Pinnock CB, Marshall VR: Does evaluation with the International Prostate Symptom Score predict the outcome of transurethral resection of the prostate? J Urol 1997;158:94-99.

10 Barry MJ, Fowler FJ, O'Leary MP: Measuring disease-specific health status in men with benign prostatic hyperplasia. Med Care 1995;33: 145-155.
11 Matthews GJ, Motta J, Fracehia JA: The accuracy of transrectal ultrasound prostate volume estimation: Clinical correlations. J Clin Ultrasound 1996;24:501-505.

12 Roehrborn CG: Accurate determination of prostate size via digital rectal examination and transrectal ultrasound. Urology 1998;51:(suppl 4A):19-22.

13 Doll H, McPherson K, Davies J, Flood A, Smith J, Williams G, Ginzler M, Petticrew M, Black N: Reliability of questionnaire responses as compared with interview in the elderly: Views of the outcome of transurethral resection of the prostate. Soc Sci Med 1991;33: 1303-1308.

14 Hakenberg OW, Pinnock CB, Marshall VR: The follow-up of patients with unfavourable early results of transurethral prostatectomy. BJU Int 1999;84:799-804.

15 Chen SS, Hong JG, Hsiao YJ, Chang LS: The correlation between clinical outcome and residual prostatic weight ratio after transurethral resection of the prostate for benign prostatic hyperplasia. BJU Int 2000;85:79-82. 